\title{
Assessment of breast cancer opportunistic screening by clinical-pathological indicators: a population-based study
}

\author{
A Bordoni ${ }^{1, *}$, NM Probst-Hensch ${ }^{2}$, L Mazzucchelli ${ }^{3}$ and A Spitale' \\ 'Ticino Cancer Registry, Institute of Pathology, Via in Selva 24, Locarno CH-6600, Switzerland; '2Department of Chronic Disease Epidemiology/NICER, \\ ISPM Zurich, University of Zürich, Sumatrastrasse 30, Zurich CH-8006, Switzerland; ${ }^{3}$ Institute of Pathology, Via in Selva 24, Locarno CH-6600, \\ Switzerland
}

\begin{abstract}
BACKGROUND: Although some clinical-pathological features of breast cancers, such as the incidence of ductal cancer in situ (DCIS) and the diameter of invasive tumours, are sensitive indicators of early detection, comprehensive population-based studies of opportunistic screening are needed.

METHODS: Cases of DCIS or invasive breast cancer diagnosed in 1996-2007 were identified from the Ticino Cancer Registry (south of Switzerland). Time trends of age-adjusted incidence and mortality, as well as main clinical-pathological features, such as tumour diameter, AJCC stage and histological grade, were analysed.

RESULTS: A total of 3047 incident cases of female breast cancer were identified. The proportion of DCIS with respect to invasive cases increased from 5.8\% in the period 1996-2001 to 6.4\% in the period 2002-2007. The median tumour size of invasive cancers decreased from $20 \mathrm{~mm}$ in 1996-200 I to $18 \mathrm{~mm}$ in 2002-2007 ( $<<0.000 \mathrm{I})$. An increase in well/moderately differentiated invasive tumours, from 67\% in the period 1996-200I to 73\% in 2002-2007 ( $<<0.001$ ), was detected and resulted in an Annual Percentage Change of incidence of 2.8 (95\% confidence interval: 1.3; 4.3).

CONCLUSION: An opportunistic screening strategy can lead to an improvement of prognostic features at diagnosis, but these features are still less favourable than those achieved by organised screening programmes.

British Journal of Cancer (2009) I 01, 1925-1931. doi:10.1038/sj.bjc.6605378 www.bjcancer.com

Published online 27 October 2009

(c) 2009 Cancer Research UK
\end{abstract}

Keywords: breast cancer; opportunistic screening; cancer registry; DCIS; tumour size; histological grade

Owing to the difficulty in implementing primary preventive measures for breast cancer, secondary prevention is correspondingly important, aimed at maximising detection of small cancers. Early detection diminishes the likelihood of clinical symptoms, disease progression, recurrence, distant metastasis, and death from breast cancer (Tabar et al, 1999). Trials have concluded that mammography screening in women aged from 50 to 69 can reduce breast cancer mortality by $25-30 \%$ (Gotzsche and Nielsen, 2006). Although Swiss French-speaking regions are covered by organised screening, the German- and Italian-speaking regions have no such programme. In the Italian- and French-speaking parts, physician-prescribed mammography is more frequent than in the German-speaking parts (Keller et al, 2001). In the south of Switzerland, the proportion of women aged 50-64 years who had undergone at least one mammography examination increased from $85 \%$ in 2002 to $88 \%$ in 2007 (Federal Office of Statistics, 2008).

The current coexistence of systematic screening programmes and opportunistic screening strategies in Switzerland with its highquality health-care system provides an opportunity to investigate the merits and drawbacks of the two approaches (Zwahlen et al,

*Correspondence: Dr A Bordoni; E-mail: andrea.bordoni@ti.ch Received 24 July 2009; revised 13 September 2009; accepted 28 September 2009; published online 27 October 2009
2004). Although both methods seem effective in reducing breast cancer mortality, data on opportunistic screening are limited (de Gelder et al, 2009).

The aim of this ecological population-based study was to assess such indicators as incidence rates, percentage of small cancers, stage distribution at diagnosis, axillary lymph node status and corresponding time trends for newly detected breast cancers, and to compare our data with those from populations with programmed screening.

\section{MATERIALS AND METHODS}

Patients with a primary diagnosis of ductal cancer in situ (DCIS) or invasive breast cancer diagnosed between 1996 and 2007 were selected from the Ticino Cancer Registry located in the south of Switzerland, where more than $80 \%$ of women aged 50-69 years regularly undergo mammography (Bordoni and Mazzola, 2007; Bordoni et al, 2009).

Topography and morphology classifications followed the International Classification of Diseases for Oncology (ICD-O-III) and the WHO Classification of Breast Tumours (Fritz et al, 2000; Tavassoli and Devilee, 2003). Case registration followed the International Agency for Research on Cancer (IARC) guidelines and European Network of Cancer Registries (ENCR) recommendations (Tyczynski et al, 2003). 
In situ lobular neoplasia and non-epithelial cancers such as lymphoma, sarcoma and phyllodes tumours were excluded from the analysis.

Essential information was abstracted from pathology reports, including tumour diameter, lymph node status, stage group (AJCC, 5 th and 6th editions), histological grade (Bloom-Richardson system and the Elston and Ellis modification), laterality and hormonal receptor status. DCIS were graded according to nuclear features (European Commission, 1996; Shoker and Sloane, 1999). Individuals who received preoperative/neoadjuvant treatment (less than $5 \%$ ) were excluded from analyses of tumour stage and diameter. Breast cancers expressing ER and PR in less than 5\% of neoplastic cells were considered as negative for hormone receptor expression (Spitale et al, 2009). All histopathological analyses were carried out by a single laboratory and evaluated on routinely collected tissues by the same group of pathologists to ensure reproducibility.

\section{Statistical analysis}

Mean and median values were provided for quantitative variables, whereas proportions represented qualitative variables. Differences between two periods (1996-2001 vs 2002-2007) were evaluated using Student's T-test for continuous variables and $\chi^{2}$ or Fisher's exact test for discrete variables (Armitage et al, 2002). Agestandardised incidence and mortality rates were calculated by the direct method (Esteve et al, 1994). Incidence rates of invasive and in situ lesions were produced for different age groups, for the above two periods and for single calendar years. Trends in incidence and mortality were measured as the estimated annual percentage change (APC) and the 95\% confidence intervals (CIs) (Kleinbaum et al, 1988). Joinpoints representing the years when the trend changed were identified (Kim et al, 2000; National Cancer Institute, April 2005). Time trends were also analysed for mean and median tumour diameter, AJCC stage distribution (considering the shift from advanced to early stages), as well as histological grade at diagnosis. Statistical significance was determined at $P<0.05$ and the SAS System Version 9.1 (SAS Institute Inc., Cary, NC, USA) was used for analysis.

\section{RESULTS}

A total of 3047 incident cases of female breast cancer were identified in the study period, of which 187 (6.1\%) were DCIS and 2860 (93.9\%) invasive carcinomas.

Patient and invasive tumour characteristics are summarised for the two periods in Table 1. The mean patient age was 63.0 years, with no significant change during the study. About $80 \%$ of cases were diagnosed after age 50 years, those with in situ cancer being significantly younger (60.9 years) than those with invasive cancer $(P=0.0198$, data not shown); the proportion of in situ cases was higher among patients aged 50-69 years (57.7\%), with a lower proportion aged 70 years or over $(24.1 \%)$.

Among invasive cancers, we found that the mean diameter (data available for $85 \%$ of cases) decreased by $9 \%$, from $22.0 \pm 13.2$ to $20.3 \pm 12.6 \mathrm{~mm}$, between $1996-2001$ and 2002-2007 $(P=0.0008)$; the corresponding medians decreased by $11 \%$ from 20 to $18 \mathrm{~mm}$ $(P<0.0001)$. A decreasing trend of mean (APC: $-1.3 ; 95 \%$ CI: -2.1 ; -0.5 ) and median (APC:-1.5; 95\% CI: -2.5 ; -0.4 ) tumour size was detected from 1996 to 2007 . A similar but stronger pattern was observed in the age group 50-69 years, with a significant reduction in mean (APC: $-2.1 ; 95 \%$ CI: $-3.1 ;-1.1$ ) and median size (APC: $-2.5 ; 95 \%$ CI: $-3.9 ;-1.1$ ). We also noted an increase in the number of tumours with a diameter $\leqslant 10 \mathrm{~mm}$ or $11-20 \mathrm{~mm}$ in the more recent period, whereas cases with a diameter greater than $20 \mathrm{~mm}$ declined, both at all ages $(P=0.0441$, Table 1$)$ and in the age group 50-69 years $(P=0.1821$, data not shown).
Overall, $40 \%$ of invasive cancers were associated with lymph node metastases at diagnosis, the respective proportions being $43.4 \%$ in women younger than 50 years, $42.3 \%$ in the age group $50-69$ years and $34.2 \%$ at age of 70 years or over (data not shown). Comparing the two periods, there was no significant change in the proportion with lymph node metastases compared with those with no nodal involvement, even after age stratification. The mean and median numbers of examined lymph nodes decreased significantly from 2001 onwards, with an APC equal to -10.5 (95\% CI: -13.8 ; $-7.0)$ and -18.7 (95\% CI: $-25.1 ;-11.8)$, respectively, the pattern being similar at the age of 50-69 years. Simultaneously, the use of sentinel node procedure increased from zero in 1996 to $60.4 \%$ in 2007 (data not shown). Only 6\% of invasive cancers presented distant metastases at diagnosis with no significant trend over the study period.

More than $80 \%$ of invasive cases were diagnosed at stage I or II. The proportion of women with stage I increased from $38.1 \%$ in $1996-2001$ to $42.2 \%$ in 2002-2007 (Table 1) with similar results for ages 50-69 years, with a higher percentage of stage I cases in the last period $(40.4 \%$ in $1996-2001$ vs $45.7 \%$ in $2002-2007$, $P=0.3197)$. The results were confirmed when age-standardised incidence trends were observed (Figure 1).

Well/moderately differentiated invasive lesions increased (from $67 \%$ in $1996-2001$ to $73 \%$ in $2002-2007)$, whereas poorly differentiated cancers declined $(P=0.0003)$; results for the age group 50-69 years were similar. An opposite but not significant trend was observed in the two periods for in situ lesions; a decrease of well/moderately differentiated cancers (from 58.3 to $44.3 \%$ ) was accompanied by an increase in poorly differentiated cancers (from 41.7 to 55.7\%). Considering the age-standardised incidence rates, we found a significant increase (APC: $2.8 ; 95 \% \mathrm{CI}$ : $1.3 ; 4.3)$ in well/moderately differentiated invasive cancers and a decrease (APC: -1.3 ; 95\% CI: $-4.7 ; 2.3$ ) in poorly differentiated invasive cancers (Figure 2). In DCIS cases, both well/moderately (APC: 13.3 ; 95\% CI: $0.5 ; 27.9$ ) and poorly (APC: 33.8 ; 95\% CI: 4.0 ; 72.3) differentiated lesions increased.

Of the 2860 new cases of invasive breast cancer diagnosed in the period 1996-2007, $1273(44.5 \%)$ occurred in women in the target age group (50-69 years) for mammography screening. The overall World age-standardised incidence rate was equal to 79.6 cases per 100000 women with an APC of 0.9 (95\% CI: -0.8 ; 2.7). The incidence trend in pre-menopausal women was substantially stable (APC: $-0.7 ; 95 \%$ CI: $-4.7 ; 3.5$ ), whereas at ages $50-69$ and $70+$ years, an increasing trend was observed, though the estimated APCs were not statistically significant.

Of the 187 DCIS, $34(18 \%)$ occurred before the age of 50 years, $108(58 \%)$ at ages $50-69$ years and the remaining $45(24 \%)$ at ages $70+$ years. The proportion of DCIS among the 3047 incident cases included in the study (DCIS and invasive tumours) increased from $5.8 \%$ in the period $1996-2001$ to $6.4 \%$ in the period $2002-2007$, and markedly in the final 2 years, when it reached $10 \%$; at ages $50-$ 69 years, this increased from $7.2 \%$ in $1996-2001$ to $8.4 \%$ in $2002-$ 2007 (data not shown).

Over the 12-year study period, the overall incidence of DCIS in Ticino was 5.7 cases per 100000 women, and this remained essentially constant until 2005 (Figure 1). The final 2-year data (2006-2007), however, suggests an increase in world age-adjusted incidence (11.5 cases per 100000), a pattern also observed after stratification by age group. The age-standardised incidence for DCIS among women in the target age group (50-69 years) increased between 1996-2001 and 2002-2007 (19.2 and 24.4 cases per 100000 , respectively); the rate for those aged 70 years or over also showed an upward trend (from 14.0 to 20.4 cases per $100000)$.

The overall age-adjusted mortality rates of breast cancer in Ticino decreased from $20-22$ cases in the 1980 s to 14.6 cases per 100000 in 2005 , with a significant APC equal to -1.4 (95\% CI: $-2.4 ;-0.5)$. Mortality below age 50 years started to decrease 
Table I Clinical-pathological characteristics of patients with invasive breast cancers. Ticino (south of Switzerland), 1996-200I vs 2002-2007

\begin{tabular}{|c|c|c|c|c|}
\hline Variable & All invasive cases, $n=2860$ & $1996-200|, n=| 328(46.4 \%)$ & $2002-2007, n=1532(53.6 \%)$ & $P$-value \\
\hline Mean \pm s.d. (years) & $63.0 \pm 14.5$ & $62.7 \pm 14.8$ & $63.3 \pm 14.3$ & 0.2915 \\
\hline Median & 63 & 62 & 63 & 0.1759 \\
\hline \multicolumn{5}{|l|}{ Age-specific groups, n (\%) } \\
\hline$<50$ & $59 \mid(20.7)$ & $284(21.4)$ & $307(20.0)$ & 0.6420 \\
\hline $50-69$ & $1273(44.5)$ & $582(43.8)$ & $691(45.1)$ & \\
\hline Post-menopausal (age > 5I), n (\%) & $2164(75.7)$ & $985(74.2)$ & $1180(77.0)$ & \\
\hline \multicolumn{5}{|l|}{ Basis of diagnosis } \\
\hline Non-microscopic & $26(0.9)$ & $9(0.7)$ & $17(1.1)$ & 0.0021 \\
\hline Cytology & $110(3.8)$ & $69(5.2)$ & $41(2.7)$ & \\
\hline Histology & $2707(94.7)$ & $1240(93.4)$ & $1467(95.8)$ & \\
\hline $\mathrm{DCO}$ & $17(0.6)$ & $10(0.7)$ & $7(0.4)$ & \\
\hline \multicolumn{5}{|l|}{ Size-specific groups, n (\%) } \\
\hline$\leqslant 1.0 \mathrm{~cm}$ & $383(15.8)$ & $165(14.6)$ & $218(16.9)$ & 0.0441 \\
\hline $1.0-2.0 \mathrm{~cm}$ & $1082(44.7)$ & $486(43.1)$ & $596(46.0)$ & \\
\hline $2.0-5.0 \mathrm{~cm}$ & $888(36.7)$ & $446(39.6)$ & $442(34.1)$ & \\
\hline$>5.0 \mathrm{~cm}$ & $69(2.8)$ & $30(2.7)$ & $30(3.0)$ & \\
\hline Unknown or set after therapy & 438 & 201 & 237 & \\
\hline \multicolumn{5}{|l|}{ Lymph node status, n (\%) } \\
\hline Positive & $1032(40.0)$ & $49 \mid(40.5)$ & $54 \mid(39.5)$ & 0.5862 \\
\hline Negative & |55| (60.0) & $721(59.5)$ & $830(60.5)$ & \\
\hline Missing or set after therapy & 277 & & & \\
\hline \multicolumn{5}{|l|}{ Clinical behaviour, n (\%) } \\
\hline Unknown or set after therapy & 316 & 110 & 206 & \\
\hline \multicolumn{5}{|l|}{ Histological type, $n$ (\%) } \\
\hline Ductal & $2308(80.7)$ & $1090(82.1)$ & $1218(79.5)$ & 0.0048 \\
\hline Lobular & $309(10.8)$ & $121(9.1)$ & $188(12.3)$ & \\
\hline Mixed ductal and lobular & $69(2.4)$ & $25(1.9)$ & $44(2.9)$ & \\
\hline Other & $174(6.1)$ & $92(6.9)$ & $82(5.3)$ & \\
\hline \multicolumn{5}{|l|}{ Histological grade (Elston/Ellis), n (\%) } \\
\hline Well/moderately differentiated & $1876(70.4)$ & $821(67.0)$ & $1055(73.3)$ & 0.0003 \\
\hline Poorly differentiated & $789(29.6)$ & $405(33.0)$ & $384(26.7)$ & \\
\hline Unknown/unclassified & 195 & 103 & 92 & \\
\hline \multicolumn{5}{|l|}{ Laterality, n (\%) } \\
\hline Right & | $357(48.3)$ & $632(48.2)$ & $725(48.3)$ & 0.9624 \\
\hline Left & $1453(51.7)$ & $678(51.8)$ & $775(51.7)$ & \\
\hline Unknown & 50 & 18 & 32 & \\
\hline \multicolumn{5}{|l|}{ ER status, $n$ (\%) } \\
\hline Positive & $2095(81.8)$ & $874(77.1)$ & $|22|(85.4)$ & $<0.0001$ \\
\hline Negative & $467(18.2)$ & $259(22.9)$ & $208(14.6)$ & \\
\hline Unknown & 298 & 195 & 103 & \\
\hline \multicolumn{5}{|l|}{ PR status, n (\%) } \\
\hline Positive & $1759(68.8)$ & $713(63.2)$ & $1046(73.1)$ & $<0.0001$ \\
\hline Negative & $799(31.2)$ & $415(36.8)$ & $384(26.9)$ & \\
\hline Unknown & 302 & 200 & 102 & \\
\hline
\end{tabular}




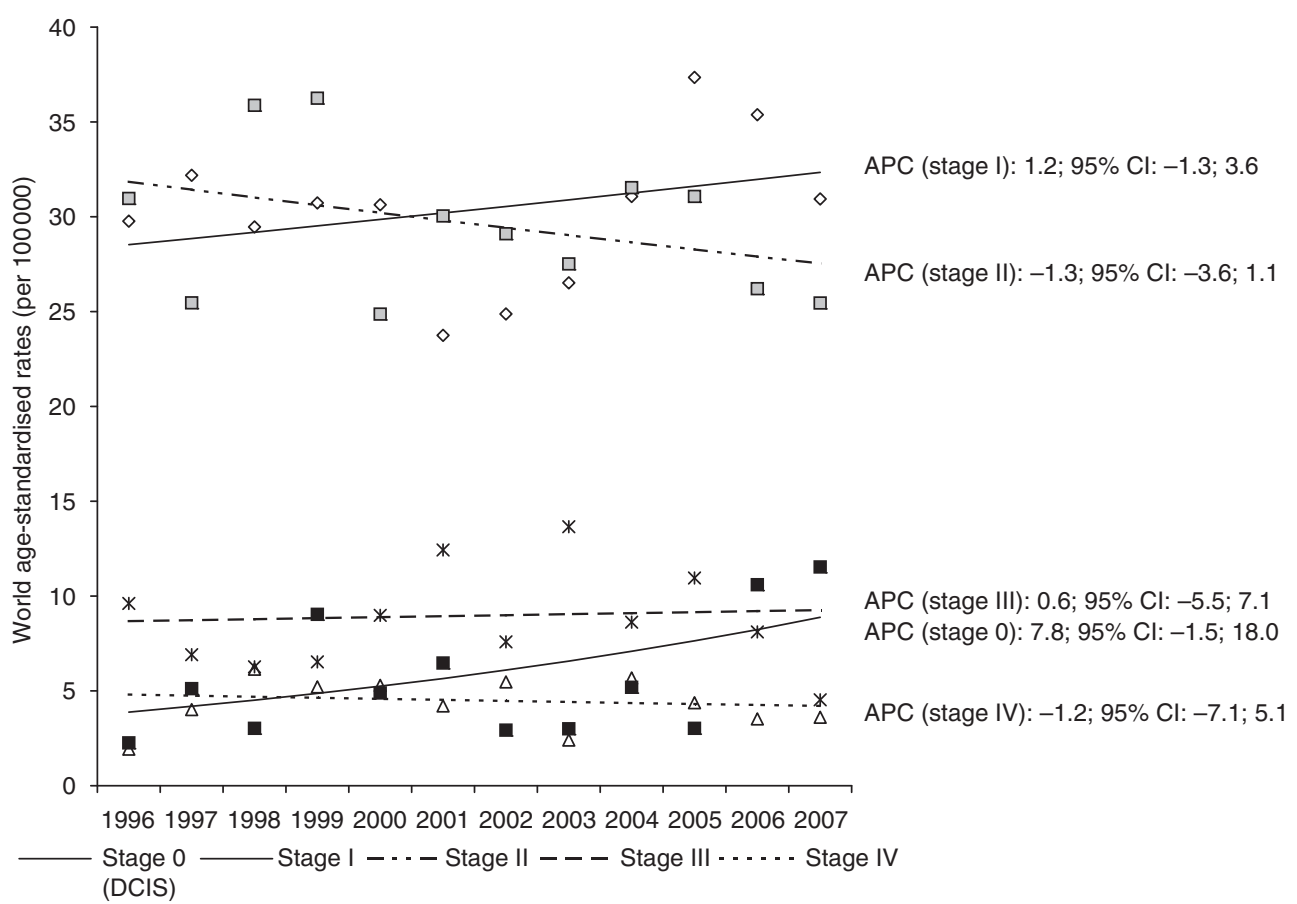

Figure I Trend of breast cancer incidence according to stage. Ticino (south of Switzerland), 1996-2007.

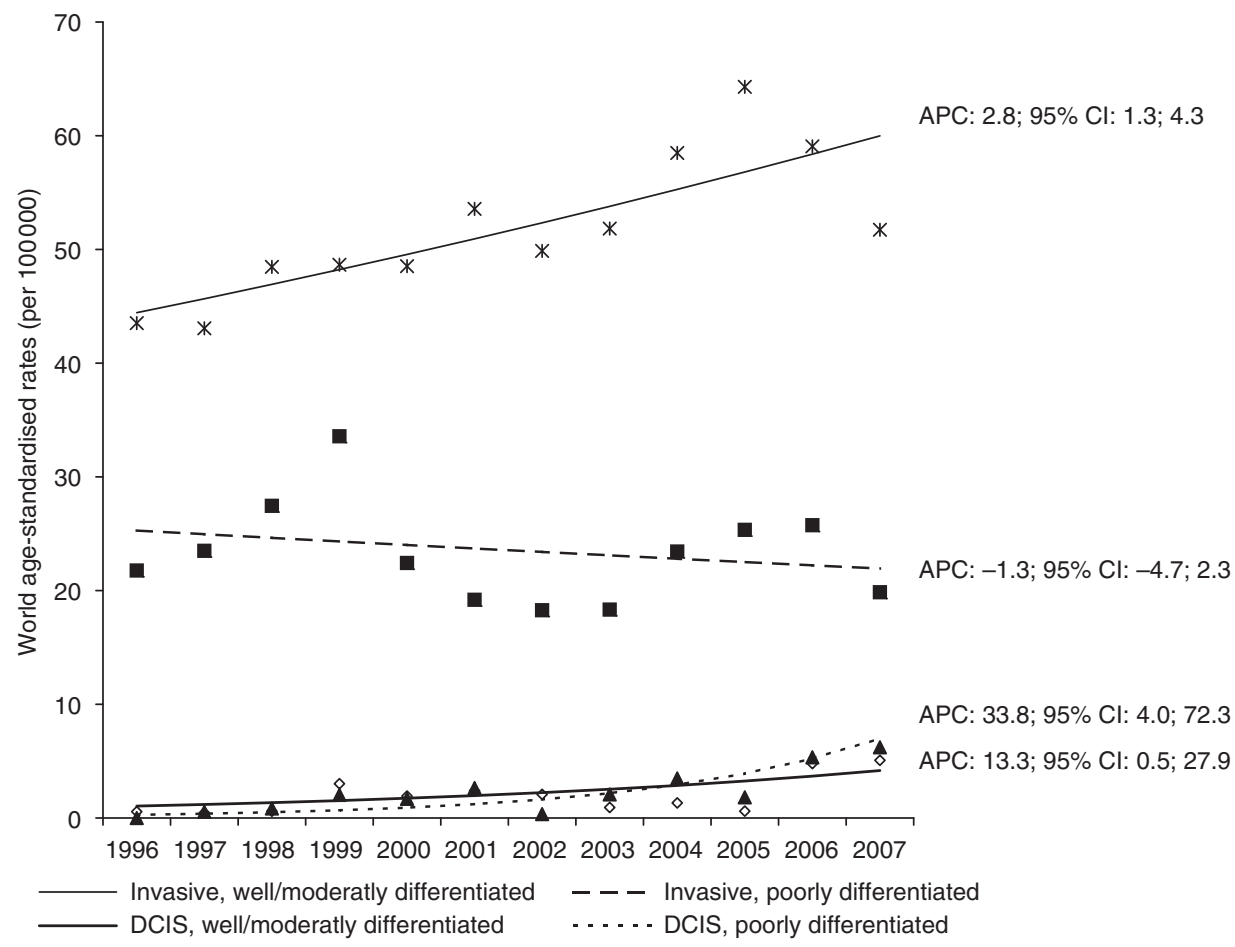

Figure 2 Incidence of invasive and in situ ductal breast cancers (DCIS), according to histological grade. Ticino (south of Switzerland), $1996-2007$.

significantly after 1998 with an APC equal to -19.2 (95\% CI: $-33.0 ;-2.6)$; a significant decrease was detected from 1990 in the age group 50-69 years (APC: -3.5 ; 95\% CI: -6.0 ; -0.9 ); however, for women aged over 69 years, there was no change in breast cancer mortality over time.

\section{DISCUSSION}

The role of cancer registries in evaluating breast cancer screening has been highlighted in recent guidelines (Perry et al, 2008), and they can also provide population-based breast cancer data 
regardless of the mode of detection, whether by an organised screening programme or by opportunistic mammography or clinical means, thereby permitting an evaluation of a screening strategy for the whole population. Normally, essential quality parameters can be produced for an organised screening programme (Swedish Organised Service Screening Evaluation Group, 2007; NHS Breast Screening Programme, 2008; Perry et al, 2008), and cancer registries can also provide early indicators of screening efficacy, without waiting for the mortality data (Schaffer et al, 1996). We focused on specific indicators, and compared our results for an opportunistic screening with data obtained from other European and US population-based studies (Table 2). It is important here to stress that the different degrees of completeness, as well as age and ethnical distribution within these studies, have to be taken into account when interpreting differences between our and other findings.

Although not statistically significant, women overall, and particularly those aged 50-69 years, showed a downward stage shift, with an increase in stage I and a slight decrease in stage II cases compatible with what we expected from the literature (Coburn et al, 2004; Louwman et al, 2008). With respect to the change of TNM classification in 2003, no significant APC in the age-adjusted incidence trend according to stage was observed, as in other studies (Louwman et al, 2008), making it unlikely that the TNM change had influenced our results. The percentage of stage I cases $(40.2 \%$ overall) was comparable to that in European regions with organised screening programmes (the Netherlands 39\%, Denmark 43\%), but was lower than that in Rhode Island, United States (53.5\%) (Coburn et al, 2004; Jensen et al, 2008; Louwman et al, 2008).

The downward stage shift observed in southern Switzerland was accompanied by a decreasing trend of invasive tumour size at the time of diagnosis. The significant decrease in both median
$(P<0.0001)$ and mean $(P=0.0008)$ diameter showed that early detection was also effective at this level. Taken together, the data suggest that an opportunistic screening here has been associated not only with an increased awareness of breast cancer in the population and among general practitioners, but also with the availability of high-quality diagnostic imaging. Nevertheless, the median and mean sizes are higher than those reported for Rhode Island, which has organised screening with $80 \%$ biannual attendance, (Table 2) (Coburn et al, 2004). Similarly, in Denmark, a median tumour with a diameter equal to $20 \mathrm{~mm}$ was observed in two regions where no organised screening was implemented, and that equal to $15 \mathrm{~mm}$ in a region where one was (Jensen et al, 2008). When we performed a subgroup analysis that considered tumour size for the period 2000-2005 (with the aim of making comparison with other studies without a period bias), the proportion of tumours with a diameter $\leqslant 10 \mathrm{~mm}$ was $18.2 \%$ in Ticino, whereas in the Cantons of Geneva and Vaud, with population-based screening, this reached 26.1 and $30.1 \%$, respectively (Table 2) (Schopper and de Wolf, 2007; Bulliard et al, 2009). In view of the difficulty in the pathological determination of the DCIS diameter, this was not analysed (Thomson et al, 2001; European Commission, 2006).

The trend, described above, of reduced tumour diameter at diagnosis should be biologically followed by a decrease in the detection of positive lymph nodes. However, we detected an essentially constant trend of positive lymph node incidence between 1996 and 2007. This finding could be attributed to competitive effects, such as the introduction of the sentinel lymph node procedure that has been adopted during recent years, as well as the improved histological workup associated with the multiple level investigation of lymph nodes, which has also been introduced by pathologists (Cserni, 1999; Kiaer et al, 2008; Madsen et al, 2008).

Table 2 Comparison of major indicators among screening programme guidelines, Ticino (south of Switzerland) data and other population-based studies

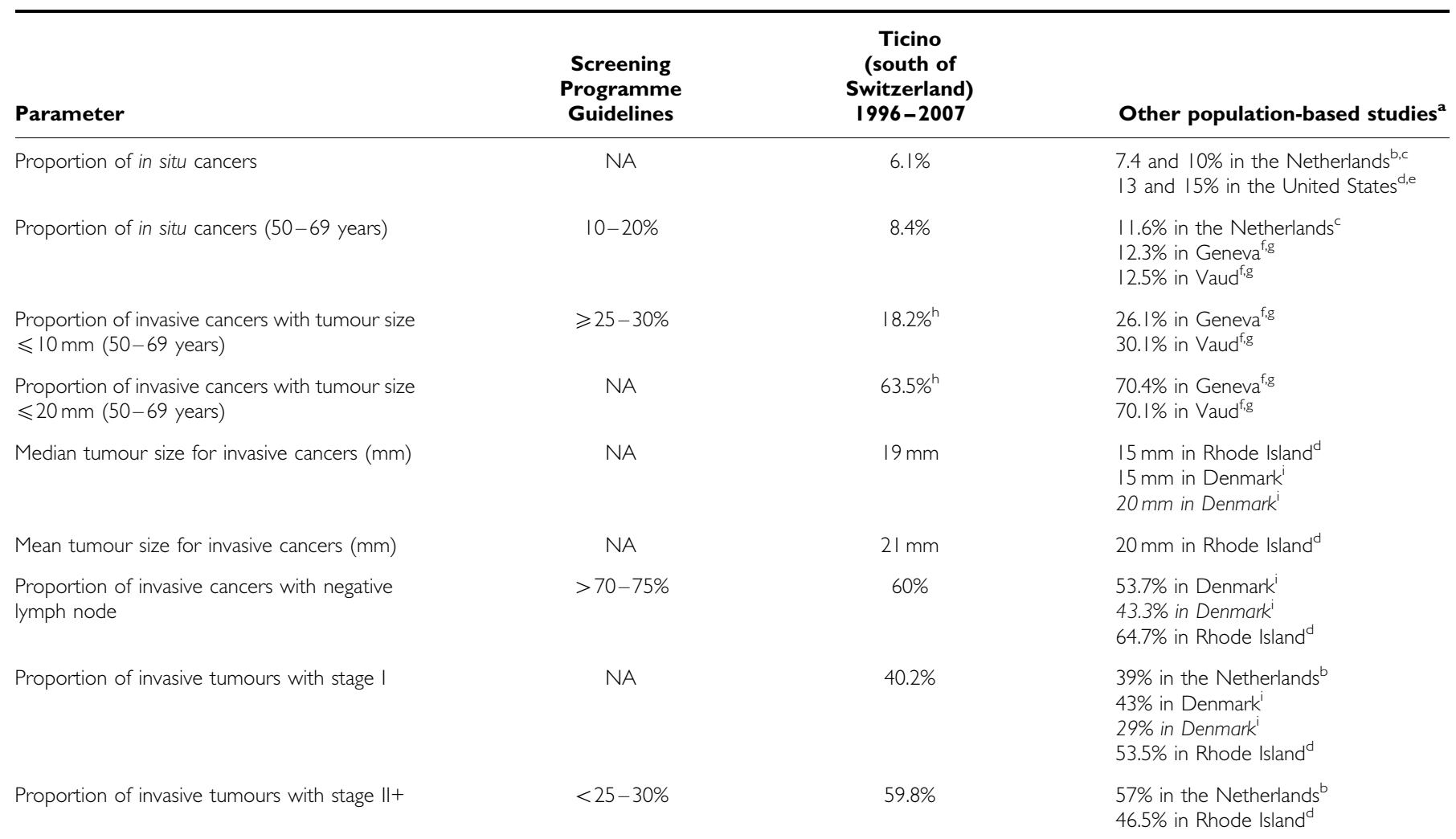

Abbreviation: $\mathrm{NA}=$ not available. ${ }^{\mathrm{a}} \mathrm{All}$ results come from regions where an organised screening programme is implemented, with the exception of those reported in italics,

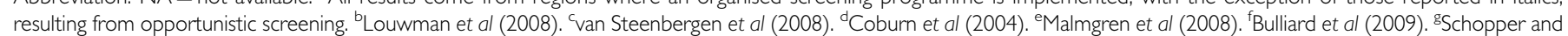
de Wolf (2007). ' Data for the period 2000-2005, with the aim of being comparable with other Swiss data (i.e., Geneva and Vaud). 'Jensen et al (2008). 
Although data are limited, poorly differentiated DCIS lesions (high grade) are probably associated with a significantly higher risk for invasive carcinoma (Vainio, 2002). High-grade DCIS shows abnormal mammography features more frequently than does lowgrade DCIS, because of more obvious calcification. We observed an increase in poorly differentiated DCIS (Figure 2) that may reflect increased use of mammography and also could represent a downstaging from invasive to in situ cancers, as hypothesised (Sumner et al, 2007). We found an increasing trend of well/ moderately differentiated invasive cases, accompanied by a decrease in high-grade cancers, that could be associated with early detection (Tabar et al, 1999; Schopper and de Wolf, 2007).

Ductal cancer in situ should increase when a screening programme is implemented (Miller et al, 2000; van Steenbergen et al, 2008) and increases have been reported from populationbased studies in the United States, Australia, Italy and the Swiss Canton of Vaud (Levi et al, 1997; Barchielli et al, 1999; Kricker et al, 2004; Li et al, 2005). In southern Switzerland, we observed, among all tumours analysed (DCIS and invasive cases), a proportion of DCIS equal to $6.4 \%$ in the period $2002-2007$, similar to that reported in two studies in the Netherlands $(10 \%$ in $2000-$ 2004 and $7.4 \%$ in 1984-2006), but our estimates are lower than in some US studies (13 and $15 \%$ in 1987-2001 and 1999-2005, respectively) (Table 2). Although a real difference in the incidence of breast lesions in Europe compared with North America cannot be excluded, it is important to highlight that the pathology criteria could be different. For the target age group $50-69$ years, our observed $8.4 \%$ of in situ cancers is close, though not equal to what was reported from the Netherlands $(11.6 \%)$, Geneva (12.3\%) and Vaud (12.5\%), where population screening programmes are implemented (Table 2). In the final 2 years of observation, the proportion of DCIS increased to $10 \%$, along with the introduction of digital mammography and vacuum-assisted needle core biopsy (Thomson et al, 2001; Pisano et al, 2005).

Considering the mortality, both earlier diagnosis because of screening and better treatment may have had a role in the

\section{REFERENCES}

Armitage P, Berry G, Matthews JNS (2002) Statistical methods in Medical Research. 4th edn. Blackwell Science Ltd: Oxford

Barchielli A, Paci E, Giorgi D (1999) Recent trends of in situ carcinoma of the breast and mammographic screening in the Florence area, Italy. Cancer Causes Control 10: 313-317

Bordoni A, Mazzola P (2007) Cancer incidence in Switzerland, Ticino (1998-2002). In: Curado MP, Edwards B, Shin HR et al (eds). Cancer Incidence in Five Continents Vol. IX. IARC Scientific Publications No. 160. IARC: Lyon

Bordoni A, Spitale A, Mazzola P (2009) Ticino Cancer Registry. Web site: http://www.ti.ch/cancer

Bulliard JL, Ducros C, Jemelin C, Arzel B, Fioretta G, Levi F (2009) Effectiveness of organised versus opportunistic mammography screening. Ann Oncol 20: $1199-1202$

Coburn NG, Chung MA, Fulton J, Cady B (2004) Decreased breast cancer tumor size, stage, and mortality in Rhode Island: an example of a wellscreened population. Cancer Control 11: 222-230

Cserni G (1999) Metastases in axillary sentinel lymph nodes in breast cancer as detected by intensive histopathological work up. J Clin Pathol 52: $922-924$

de Gelder R, Bulliard JL, de Wolf C, Fracheboud J, Draisma G, Schopper D, de Koning HJ (2009) Cost-effectiveness of opportunistic versus organised mammography screening in Switzerland. Eur J Cancer 45: $127-138$

Esteve J, Benhamou E, Raymond L (1994) Statistical Methods in Cancer Research, vol. 4. IARC Scientific Publications, World Health Organisation: Lyon

European Commission (1996) European Guidelines for Quality Assurrance in Mammography Screening. Office for Official Pubblications of the European Communities: Luxembourg declining rate observed in the United States and some European countries (Schopper and de Wolf, 2009). A decreasing trend was reported in Switzerland generally, as well as in southern Switzerland for all ages and particularly in the age group 50-69 years, irrespective of the screening programme. Most likely, mortality as a quality indicator does not have enough resolution to discriminate between systematic and opportunistic screening.

Although the introduction of mass screening is the most likely explanation for the increased incidence of particularly early stage invasive breast cancer, increasing exposure to risk factors is also relevant (Louwman et al, 2008). Factors such as younger age at menarche, older age at menopause, older age at the birth of first child, lower parity, and shorter lactation have changed adversely over the past decade and so have probably contributed to the observed increase (MacMahon, 2006). Recently, the beginning of a decline in invasive cancers has been reported, attributed both to an increase in mammography-detected in situ cases and, particularly in the United States, a contemporaneous decline in the use of hormone replacement therapy (Jemal et al, 2007; Ravdin et al, 2007; Malmgren et al, 2008). However, the increasing trend of invasive breast cancers in the south of Switzerland, together with the stage shifting described above, along with tumour diameter decrease and in situ cancer increase, seems to be because of a progressive increase in the use of early detection diagnostics.

The increasing trend of positive prognostic factors shows that opportunistic mammography screening can make a substantial contribution to breast cancer diagnosis; yet the data also show that there is room for additional improvement in early detection in comparison with features achieved where organised screening is established.

\section{Conflict of interest}

The authors declare no conflict of interest.
European Commission (2006) European Guidelines for Quality Assurrance in Mammography Screening. Office for Official Publications of the European Communities: Luxembourg. 4th edn

Federal Office of Statistics (2008) Swiss Health Survey 2007. Federal Office of Statistics: Neuchâtel

Fritz A, Percy C, Jack A, Shanmugaratnam K, Sobin L, Parkin DM, Whelan S (2000) International Classification of Diseases for Oncology. 3rd edn World Health Organization: Genève

Gotzsche PC, Nielsen M (2006) Screening for breast cancer with mammography. Cochrane Database Syst Rev CD001877

Jemal A, Ward E, Thun MJ (2007) Recent trends in breast cancer incidence rates by age and tumor characteristics among U.S. women. Breast Cancer Res 9: R28

Jensen AR, Madsen AH, Overgaard J (2008) Trends in breast cancer during three decades in Denmark: stage at diagnosis, surgical management and survival. Acta Oncol 47: 537-544

Keller B, Stutz EZ, Tibblin M, Ackermann-Liebrich U, Faisst K, ProbstHensch N (2001) Screening mammographies in Switzerland: what makes female and male physicians prescribe them? Swiss Med Wkly 131: 311 - 319

Kiaer HW, Laenkholm AV, Nielsen BB, Bjerre KD (2008) Classical pathological variables recorded in the Danish Breast Cancer Cooperative Group's register 1978-2006. Acta Oncol 47: 778-783

Kim HJ, Fay MP, Feuer EJ, Midthune DN (2000) Permutation tests for joinpoint regression with applications to cancer rates. Stat Med 19: $335-351$

Kleinbaum D, Kupper L, Muller K (1988) Applied Regression Analysis and Other Multivariable Methods. Duxbury Press: North Scituate, MA

Kricker A, Goumas C, Armstrong B (2004) Ductal carcinoma in situ of the breast, a population-based study of epidemiology and pathology. $\mathrm{Br} J$ Cancer 90: $1382-1385$ 
Levi F, Te VC, Randimbison L, La Vecchia C (1997) Trends of in situ carcinoma of the breast in Vaud, Switzerland. Eur J Cancer 33: 903-906

Li CI, Daling JR, Malone KE (2005) Age-specific incidence rates of in situ breast carcinomas by histologic type, 1980 to 2001. Cancer Epidemiol Biomarkers Prev 14: 1008-1011

Louwman WJ, Voogd AC, van Dijck JA, Nieuwenhuijzen GA, Ribot J, Pruijt JF, Coebergh JW (2008) On the rising trends of incidence and prognosis for breast cancer patients diagnosed 1975-2004: a long-term populationbased study in southeastern Netherlands. Cancer Causes Control 19: $97-106$

MacMahon B (2006) Epidemiology and the causes of breast cancer. Int J Cancer 118: $2373-2378$

Madsen AH, Jensen AR, Christiansen P, Garne JP, Cold S, Ewertz M, Overgaard J (2008) Does the introduction of sentinel node biopsy increase the number of node positive patients with early breast cancer? A population based study form the Danish Breast Cancer Cooperative Group. Acta Oncol 47: 239-247

Malmgren JA, Atwood MK, Kaplan HG (2008) Increase in mammography detected breast cancer over time at a community based regional cancer center: a longitudinal cohort study 1990-2005. BMC Cancer 8: 131

Miller AB, Baines CJ, To T, Wall C (2000) Screening mammography re-evaluated. Lancet 355: 747; author reply 752

National Cancer Institute (April 2005) Joinpoint Regression Program. Version 3.0

NHS Breast Screening Programme (2008) Annual Review 2008. Saving Lives through Screening. NHS Breast Screening Programme: Sheffield

Perry N, Broeders M, de Wolf C, Tornberg S, Holland R, von Karsa L (2008) European guidelines for quality assurance in breast cancer screening and diagnosis. Fourth edition-summary document Ann Oncol 19: 614-622

Pisano ED, Gatsonis C, Hendrick E, Yaffe M, Baum JK, Acharyya S, Conant EF, Fajardo LL, Bassett L, D’Orsi C, Jong R, Rebner M (2005) Diagnostic performance of digital versus film mammography for breast-cancer screening. N Engl J Med 353: 1773-1783

Ravdin PM, Cronin KA, Howlader N, Berg CD, Chlebowski RT, Feuer EJ, Edwards BK, Berry DA (2007) The decrease in breast-cancer incidence in 2003 in the United States. N Engl J Med 356: 1670-1674

Schaffer P, Renaud R, Gairard B, Guldenfels C (1996) The role of cancer registries in the evaluation of breast cancer screening. Rev Epidemiol Sante Publique 44(Suppl 1): S15-S21
Schopper D, de Wolf C (2007) Breast Cancer screening by Mammography: International Evidence and the Situation in Switzerland. Swiss Cancer League, Oncosuisse: Bern

Schopper D, de Wolf C (2009) How effective are breast cancer screening programmes by mammography? Review of the current evidence. Eur J Cancer 45: $1916-1923$

Shoker BS, Sloane JP (1999) DCIS grading schemes and clinical implications. Histopathology 35: $393-400$

Spitale A, Mazzola P, Soldini D, Mazzucchelli L, Bordoni A (2009) Breast cancer classification according to immunohistochemical markers: clinicopathologic features and short-term survival analysis in a population-based study from the South of Switzerland. Ann Oncol 20: $628-635$

Sumner III WE, Koniaris LG, Snell SE, Spector S, Powell J, Avisar E, Moffat F, Livingstone AS, Franceschi D (2007) Results of 23810 cases of ductal carcinoma-in-situ. Ann Surg Oncol 14: 1638-1643

Swedish Organised Service Screening Evaluation Group (2007) Effect of mammographic service screening on stage at presentation of breast cancers in Sweden. Cancer 109: 2205-2212

Tabar L, Duffy SW, Vitak B, Chen HH, Prevost TC (1999) The natural history of breast carcinoma: what have we learned from screening? Cancer 86: 449-462

Tavassoli FA, Devilee P (2003) Pathology and Genetics of Tumours of the Breast and Female Genital Organs. IARC Press: Lyon

Thomson JZ, Evans AJ, Pinder SE, Burrell HC, Wilson AR, Ellis IO (2001) Growth pattern of ductal carcinoma in situ (DCIS): a retrospective analysis based on mammographic findings. Br J Cancer 85: 225-227

Tyczynski JE, Démaret E, Parkin DM (2003) Standards and guidelines for cancer registration in Europe. The ENCR Recommendations. Vol. I. IARC Technical Publication n.40 IARC: Lyon

Vainio H (2002) Breast Cancer Screening. IARC Handbooks of Cancer Prevention. Vol. 7 IARC Press: Lyon

van Steenbergen LN, Voogd AC, Roukema JA, Louwman WJ, Duijm LE, Coebergh JW, van de Poll-Franse LV (2008) Screening caused rising incidence rates of ductal carcinoma in situ of the breast. Breast Cancer Res Treat 115(1): 181-183

Zwahlen M, Bopp M, Probst-Hensch NM (2004) Mammography screening in Switzerland: limited evidence from limited data. Swiss Med Wkly 134: $295-306$ 